\title{
Evaluation of Results after Flexor Digitorum Superficialis Tendon Transfer to Provide Fingers and Thumb Extension in Radial Nerve Lesions
}

\author{
WAEL M. AYAD, M.D.; AHMAD TAHA, M.D.; MAHMOUD NASEF, M.D. and KHALLAD SHOLKAMY, M.Sc.
}

The Department of Plastic \& Burn Surgery, Faculty of Medicine, Al-Azhar University, Cairo

\begin{abstract}
Purpose: Objective and subjective evaluation of the results of flexor digitorum superficialis tendon transfer for the restoration of finger extension in irreparable radial nerve lesions.

Methods: Restoration of finger extension, thumb extension, was done in 10 patients (seven with radial nerve and three with posterior interossius nerve injury; age range: 5-60 years).

We used tendon transfer technique using the flexor digitorum superficialis (FDS) 3 [to extensor pollicis longus (EPL)] and FDS 4 [to extensor digitorum communis (EDC)] as donors for the reconstruction of fingers and thumb extension (all patients) and pronator teres (PT) for wrist extension.

Results: Eight patients (out of 10) yielded 'Excellent to good' results: These patients showed marked improvement to the motor power scoring M4-M5 on the MRC grading system while 2 patients (out of 10) yielded 'Fair' results: Moderate improvement to the motor power scoring M3 on the MRC grading system.
\end{abstract}

Conclusions: The FDS transfer provides thumb extension independent from the fingers and wrist extension, because the FDS control for each finger is independent from the other fingers.

Key Words: Flexor digitorum superficialis - Tendon transfer - Radial nerve.

\section{INTRODUCTION}

Tendon transfers follow a basic concept that nothing new is created but functional parts are rearranged into the best possible working combination so it is the relocation of a tendon from a functioning muscle to replace an injured or nonfunctional muscle-tendon unit [1].

Several factors are considered when choosing an appropriate tendon transfer to restore hand muscle function: The tendon transfer route and the tendon insertion site. Other factors such as tissue equilibrium, timing of the tendon transfer, joint mobility, the relative power and amplitude of the transferred muscle tendon unit, and synergism. Principles and rules must be followed in tendon transfer [2].
The aim of this study is to evaluate the results after the use of flexor digitorum superficialis in tendon transfer after radial nerve palsy.

\section{PATIENTS AND METHODS}

Ten patients were included in this study. Those patients presented to the outpatient clinics of plastic surgery at Al-Azhar University (Al-Hussin and Bab Al-Sheeryia) Hospitals. They initially presented during the period starting May 2014 to May 2017.

Ten patients with radial nerve palsy were included in the study, of which three patients had posterior interosseous nerve (PIN) affection, leading to loss of thumb and fingers extension.

The other seven patients had high radial nerve affection, leading to wrist drop in addition to the lost extension of the thumb and fingers. The loss of wrist extension in those patients further impaired the thumb and fingers function, due to frailer flexion; and thus weakened the hand power grip. Six patients were injured in their right hand (dominant), while four were injured in their left hand (all non-dominant). patients were assessed by the range of motion of wrist, thumb, and Fingers (Tables 1,2).

Table (1): Criteria for range of motion of wrist, thumb, and fingers [3].

\begin{tabular}{llccc}
\hline & Excellent & Good & Fair & Poor \\
\hline Wrist extension & $0-80$ & 0 & $\begin{array}{c}45 \text { extension } \\
\text { lag }\end{array}$ & $\begin{array}{c}\text { 70 extension } \\
\text { lag }\end{array}$ \\
Finger extension & $0-10$ & 0 & $\begin{array}{c}45 \text { extension } \\
\text { lag }\end{array}$ & $\begin{array}{c}90 \text { extension } \\
\text { lag }\end{array}$ \\
Thumb extension & $100-80$ & $80-60$ & $60-30$ & $30-0$ \\
Wrist flexion & Full & $0-20$ & 0 & Dorsiflexion \\
\hline
\end{tabular}


Table (2): Subjective evaluation scale [4].

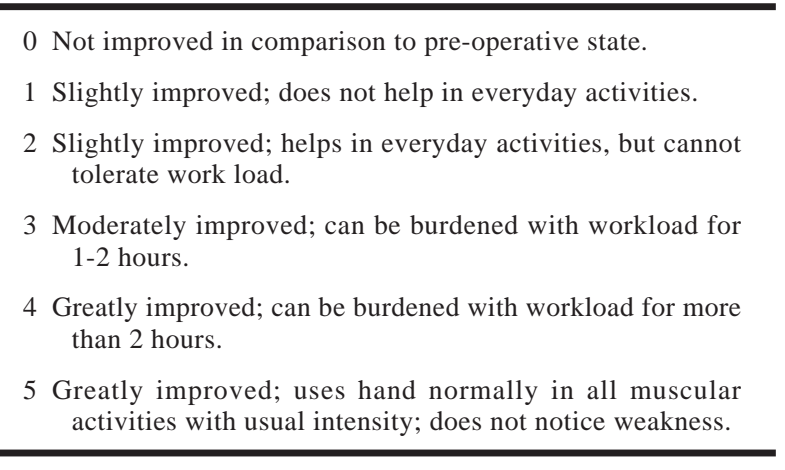

\section{Objective evaluation:}

\section{Subjective evaluation:}

Post-operative management and rehabilitation:

The splint was removed after 4-5 weeks postoperatively, Physiotherapy program was carried out by a therapist experienced in hand therapy. Range of motion exercises started at 5-6 weeks post-operatively. All exercises were passive at first, and then attempts for active motion started about two weeks later. Reeducation exercises started concomitantly for the FDS powered transfers, patients were taught to fire the transfer by trying to independently flex his ring and middle fingers.

\section{RESULTS}

This series included ten patients with radial palsy transfers; seven of whom suffered from high radial palsy, while the other three suffered from posterior interossious nerve (PIN) palsy, Table (3).

\section{- 8 patients (out of 10) yielded 'Excellent to good' results:}

Patients who underwent tendon transfers with 'early' timing obtained 'excellent to good" results.

These patients showed marked improvement to the motor power scoring M4-M5 on the MRC grading system, i.e. they obtained full range of thumb extension with reasonable power against resistance.

\section{- 2 patients (out of 10) yielded 'Fair' results:}

These patients showed moderate improvement to the motor power scoring M3 on the MRC grading system, i.e. they obtained some thumb extension against gravity.

Table (3): Data about ten patients with radial palsy transfers.

\begin{tabular}{clllll}
\hline Case & $\begin{array}{c}\text { Level of } \\
\text { injury }\end{array}$ & $\begin{array}{c}\text { Timing of } \\
\text { surgery }\end{array}$ & Mode of trauma & $\begin{array}{c}\text { Subjective } \\
\text { evaluation } \\
\text { scale }\end{array}$ & $\begin{array}{c}\text { Objective } \\
\text { evaluation }\end{array}$ \\
\hline 1 & High radial & Conventional & Cut wound & 3 & Fair \\
2 & High radial & Early & Cut wound & 4 & Good \\
3 & PIN & Conventional & Cut wound & 5 & Excellent \\
4 & High radial & Early & Cut wound & 4 & Excellent \\
5 & High radial & Early & Fracture mid-shaft humerus & 4 & Good \\
6 & PIN & Conventional & Radial head dislocation & 5 & Excellent \\
7 & High radial & Early & Cut wound & 4 & Excellent \\
8 & High radial & Early & Cut wound & 5 & Good \\
9 & PIN & Conventional & Cut wound & 5 & Excellent \\
10 & High radial & Conventional & Bullet injury & 2 & Fair \\
\hline
\end{tabular}

Surgical techniques:

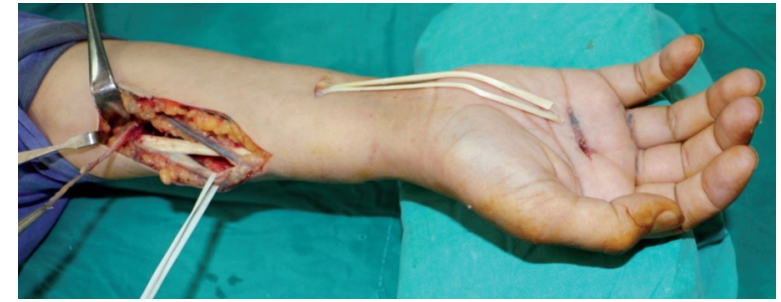

Fig. (1): The flexor digitorum superficialis to middle and ring, pronator teres are harvested and identified.

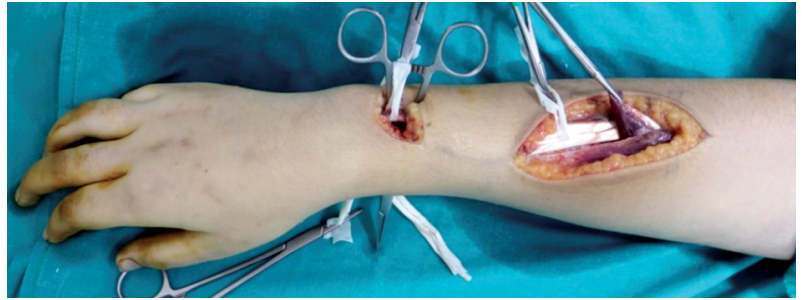

Fig. (2): Demonstration of the interossius tunnel. 


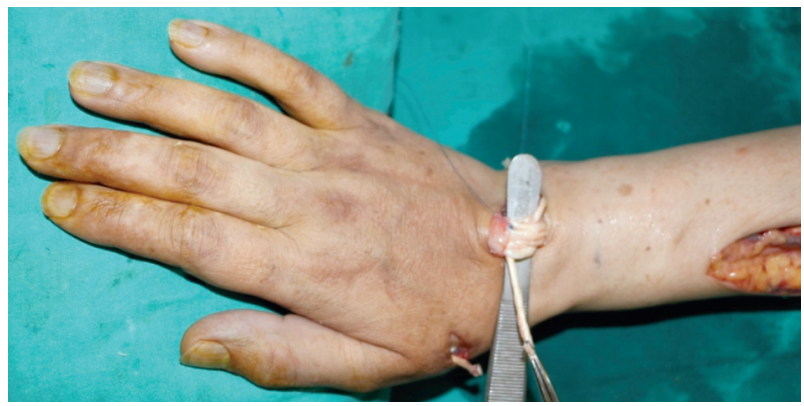

Fig. (3): A Pulvertaft weave of the flexor digitorum superficialis of the ring and middle to extensor digitorum and extensor policis respectively.

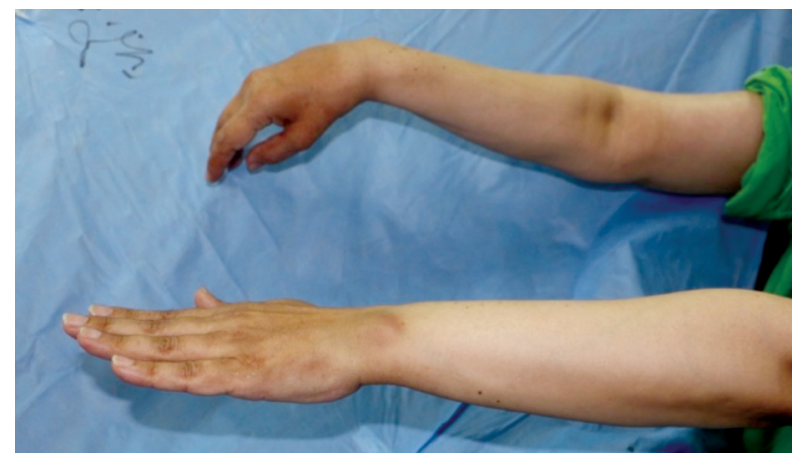

Fig. (5): Pre-operative wrist and fingers drop of right hand after radial nerve injury.

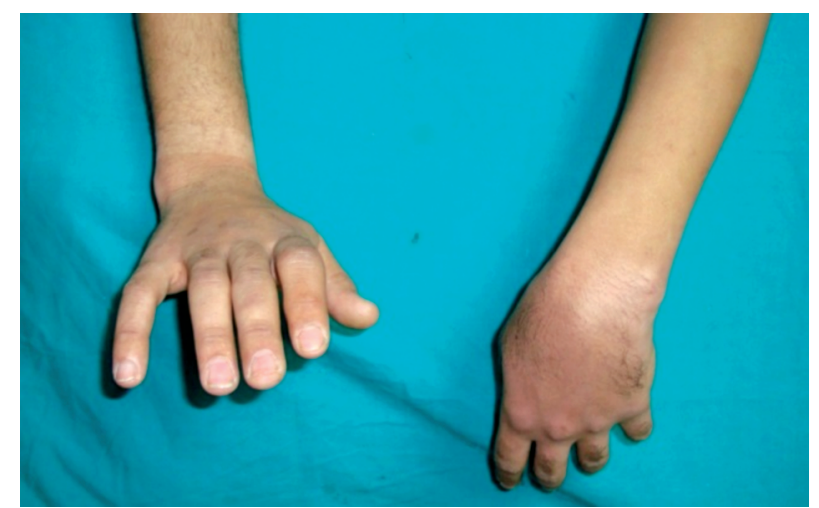

Fig. (7): Pre-operative wrist and fingers drop of left hand after radial nerve injury.

\section{DISCUSSION}

Non-cooperative, non-compliant patients or those who did not accept the labor-intensive preand post-operative physiotherapy program were not considered candidates for tendon transfer procedures.

The selection of patients indicated for tendon transfers, and the decision of the timing of their surgeries, were very meticulously done. It is always borne in mind that a tendon transfer reconstructs a lost function at the expense of a donor motor unit.

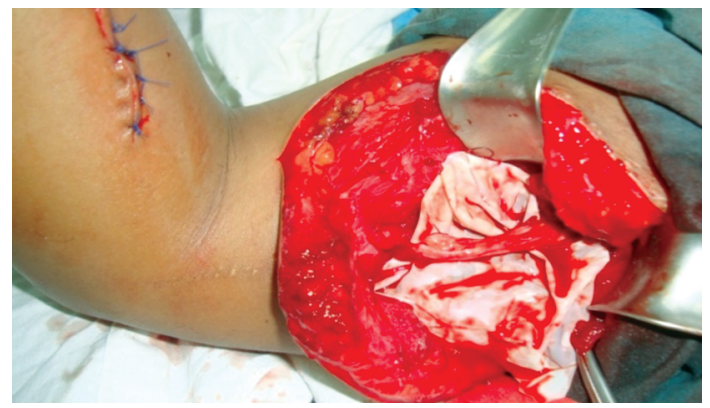

Fig.(4): Nerve grafting and tendon transfer done simultaneously.

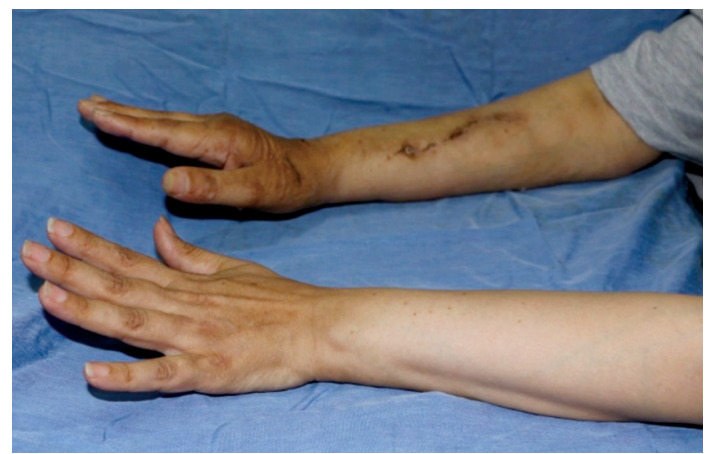

Fig. (6): Post-operative result with restoration of wrist and fingers extension.

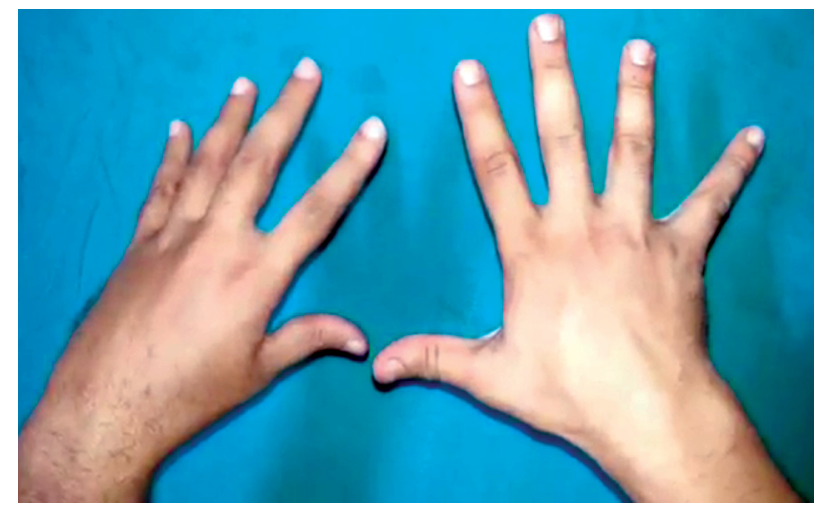

Fig. (8): Post-operative result with restoration of wrist and fingers extension 1 year later.

Interosseous tunnel make a physiological, biomechanical vector of pull. If this is done, a large window should be created in the interosseous membrane to prevent constriction or tethering of the transfer [5].

Choosing to perform a delayed nerve repair or graft, that was of a clearly poor prognosis from the start, rather than a tendon transfer, would mean wasting 6 more months for the patient, waiting for an unwarranted result.

The FDS transfer set was primarily employed; as it provides thumb extension independent from 
the fingers and wrist extension, because the FDS control for each finger is independent from the other fingers, as advocated by Boyes [5].

The FDS of the middle finger was preferred as a motor for the EPL. When the FDS is used as a motor, it provides $7 \mathrm{~cm}$ of excursion, while the FCR provides only $3 \mathrm{~cm}$; therefore, the FDS is more efficient, noting that the EPL normally provides $5 \mathrm{~cm}$ excursion. The FDS also provides more powerful contraction than that of the PL $[7,8]$.

The FDS tendon was harvested proximal to their bifurcation through a window between the A1 and A2 pulleys as originally recommended by North \& Littler, to avoid injury to the vincula or to the flexor sheath, and to leave behind a $3-\mathrm{cm}$ length of superficialis tendon that glides freely within the flexor sheath. Using this method, we did not encounter any case of PIP joint flexion contracture in the donor digit, or any swan neck deformities as in the study conducted by Altintas et al., [9].

$89 \%$ of patients with radial palsy were able to resume working after tendon transfer. In the study by Gousheh and Arasteh 92\% of the patients reintegrated into working life. In the study by Moussavi, et al., $95 \%$ of the patients experienced functional improvement [3-10].

The 3-6 months timing for return to work or resumption of everyday life activities achieved by radial palsy patients in this study, is also consistent with the literature [8].

Communication among physician, therapist, and patient is necessary to maximize the outcome and prevent untoward complications.

\section{REFERENCES}

1- Davis T.: Principles of Tendon Transfers of Median, Radial, and Ulnar Nerves, Green's Operative Hand Surgery, 7 ed: Elsevier, p. 1023, 2017.

2- Wolter K.G.: Nerve Injuries, Compression Syndromes, and Tendon Transfers, Michigan Manual of Plastic Surgery: $1^{\text {st }}$ Edition, Lippincott Williams \& Wilkins, 2004.

3- Moussavi A., Saied A. and Karbalaeikhani A.: Outcome of tendon transfer for radial nerve paralysis: Comparison of three methods. Indian. J. Orthop., 45 (6): 558-562, 2011.

4- Krishnan K.G., M.D. and Schackert G., M.D., Ph.D.: An analysis of results after selective tendon transfers through the interosseous membrane to provide selective finger and thumb extension in chronic irreparable radial nerve lesions, Elsevier, 223-231, 2008.

5- Richards R.R.: Tendon transfers for failed nerve reconstruction. Clin, Plast, Surg., 30 (2): 223-245, vi, 2003.

6- Boyes H.J.: Tendon transfers for radial palsy. Bull. Hosp. Joint. Dis., 21: 97, 1960.

7- Jones N.F. and Khiabani K.T.: Tendon transfers in the upper limb; In Mathes S.J. and Hentz V.R. (Eds.), Plastic Surgery., 2 ed., Philadelphia: Saunders, Vol. VIII, p. 453487. 2006.

8- Ingari J.V. and Green D.P.: Radial nerve palsy; In Wolfe S.W., Hotchkiss R.N., Pederson W.C. and Kozin S.H. (Eds.), Green's Operative Hand Surgery., 6 ed., Churchill Livingstone, p. 1075-1092, 2010.

9- Altintas A.A., Altintas M.A., Gazyakan E., Gohla T., Germann G. and Sauerbier M.: Long-term results and the Disabilities of the Arm, Shoulder, and Hand score analysis after modified Brooks and D'Aubigne tendon transfer for radial nerve palsy. J. Hand. Surg. Am., 34 (3): 474-478, 2009.

10- Gousheh J. and Arasteh E.: Transfer of a single flexor carpi ulnaris tendon for treatment of radial nerve palsy. J. Hand. Surg. Br., 31 (5): 542-546, 2006. 